\title{
A streptococcal effector protein that inhibits Porphyromonas gingivalis biofilm development
}

\author{
Correspondence \\ Mary E. Davey \\ mdavey@forsyth.org
}

Received 16 June 2010

Revised 2 August 2010

Accepted 9 August 2010

\author{
Aaron B. Christopher, ${ }^{2}$ Annette Arndt, ${ }^{1}$ Carla Cugini ${ }^{2}$ and Mary E. Davey ${ }^{2}$ \\ ${ }^{1}$ Institute of Microbiology and Biotechnology, University of Ulm, Ulm, Germany \\ ${ }^{2}$ Department of Molecular Genetics, The Forsyth Institute, Boston, MA, USA
}

\begin{abstract}
Dental plaque formation is a developmental process involving cooperation and competition within a diverse microbial community, approximately $70 \%$ of which is composed of an array of streptococci during the early stages of supragingival plaque formation. In this study, 79 cell-free culture supernatants from a variety of oral streptococci were screened to identify extracellular compounds that inhibit biofilm formation by the oral anaerobe Porphyromonas gingivalis strain 381. The majority of the streptococcal supernatants (61 isolates) resulted in lysis of $P$. gingivalis cells, and some (17 isolates) had no effect on cell viability, growth or biofilm formation. One strain, however, produced a supernatant that abolished biofilm formation without affecting growth rate. Analysis of this activity led to the discovery that a $48 \mathrm{kDa}$ protein was responsible for the inhibition. Protein sequence identification and enzyme activity assays identified the effector protein as an arginine deiminase. To identify the mechanism(s) by which this protein inhibits biofilm formation, we began by examining the expression levels of genes encoding fimbrial subunits; surface structures known to be involved in biofilm development. Quantitative RT-PCR analysis revealed that exposure of $P$. gingivalis cells to this protein for $1 \mathrm{~h}$ resulted in the downregulation of genes encoding proteins that are the major subunits of two distinct types of thin, single-stranded fimbriae (fimA and $m f a 1$ ). Furthermore, this downregulation occurred in the absence of arginine deiminase enzymic activity. Hence, our data indicate that $P$. gingivalis can sense this extracellular protein, produced by an oral streptococcus (Streptococcus intermedius), and respond by downregulating expression of cell-surface appendages required for attachment and biofilm development.
\end{abstract}

\section{INTRODUCTION}

High cell density and microbial diversity are fundamental to the development and function of the oral biofilm (Kolenbrander et al., 2002). The close proximity of cells within the biofilm facilitates cell-cell interactions, while the diversity offers a wide variety of metabolic functions, allowing the community to acquire nutrients and persist. During plaque formation, organisms affect the activities of one another via physical associations and through the release of extracellular molecules; the effects of these interactions range from mutualistic to antagonistic (Davey \& Costerton, 2006; Socransky \& Haffajee, 2000). Molecules that are excreted by bacteria into the environment or directly into host cells (through either non-classical or conventional secretion pathways), affecting gene expression of another organism, are often referred to as effectors. The primary objective of this study was to identify effectors produced by oral streptococci that modulate biofilm formation by the oral anaerobe Porphyromonas gingivalis.

Abbreviations: ADI, arginine deiminase; DMSO, dimethyl sulfoxide; MWCO, molecular mass (weight) cut-off; $\mu \mathrm{LC}$, microcapillary liquid chromatography; GPCR, quantitative reverse-transcription PCR.
P. gingivalis is a Gram-negative anaerobe that persists within the oral biofilm community. Outgrowth of this normally commensal organism is associated with severe periodontal disease, resulting in the destruction of tissues that support the gums and, ultimately, tooth loss (Choi et al., 1990; Dzink et al., 1988; Grossi et al., 1994; Lamont \& Yilmaz, 2002; Moore et al., 1991). Several studies have shown that $P$. gingivalis can invade and multiply within gingival epithelial cells, as well as penetrate deeper epithelial cell layers, releasing the whole organism and/or virulence factors into the bloodstream (reviewed by Yilmaz, 2008). Given its largely benign lifestyle as a part of the normal microbiota, with its ability to shift and become highly destructive, $P$. gingivalis may be best classified as a 'commensal pathogen' (Falkow, 2006). Understanding the mechanisms that control the colonization and outgrowth of this anaerobe within the oral biofilm community is fundamental to understanding the development of periodontal disease.

Oral streptococci have the capacity to produce more interspecies modulators than any other bacterial group within the oral biofilm community (Kuramitsu et al., 2007). Some, under certain growth conditions, produce 
significant quantities of hydrogen peroxide, which has antagonistic effects on a wide variety of isolates (Barnard \& Stinson, 1999; Jakubovics et al., 2008; Kreth et al., 2005). In addition, many streptococci produce bacteriocins that kill select organisms, often causing lysis. The most widely studied oral streptococcus species, Streptococcus mutans, produces five distinct peptide bacteriocins (mutacins I to $\mathrm{V}$ ), while nine more putative bacteriocin-encoding genes have been identified in its genome (Chikindas et al., 1995; Kuramitsu et al., 2007; Qi et al., 1999, 2001). In addition, another oral species, Streptococcus salivarius, produces the lantibiotic salivaricin A, which inhibits the growth of a variety of streptococcal species (Kuramitsu et al., 2007; Upton et al., 2001). Recently, a novel contact-dependent signalling system was identified between $P$. gingivalis and Streptococcus cristatus, involving a surface-associated arginine deiminase. Early studies discovered that a cell-wall protein of $S$. cristatus repressed expression of fimA (encoding the major subunit of long fimbriae) in $P$. gingivalis (Xie et al., 2000). Later studies identified the protein as an arginine deiminase (Xie et al., 2007).

In the present study, we describe the isolation and characterization of a secreted/excreted arginine deiminase isolated from culture supernatants of a clinical strain identified as Streptococcus intermedius. We show that this arginine deiminase represses expression of genes encoding proteins that are the major subunits of two different fimbrial structures present on the surface of $P$. gingivalis, the short ( $m f a 1)$ and long fimbriae $(\operatorname{fim} A)$. We also show that this arginine deiminase prevents mono-species biofilm development by $P$. gingivalis strain 381 .

\section{METHODS}

Strains and culture conditions. Seventy-nine uncharacterized streptococci (isolated on blood agar plates from adolescent supragingival plaque samples in $\mathrm{Dr}$ Anne Tanner's laboratory at the Forsyth Institute) were grown overnight in Brain Heart Infusion (BHI) broth supplemented with $0.1 \%$ yeast extract. To obtain cellfree supernatants, the cultures (final $\mathrm{pH}$ 7.2-7.4) were grown to stationary phase, centrifuged to remove bacterial cells and then filtersterilized. The isolates were maintained in a COY anaerobic chamber on trypticase soy agar plates supplemented with $5 \%$ defibrinated sheep blood (Northeast Laboratory Services, Waterville, ME, USA), $1 \mu \mathrm{g}$ haemin $\mathrm{ml}^{-1}$ and $1 \mu \mathrm{g}$ menadione $\mathrm{ml}^{-1}$ (BAPHK). P. gingivalis strain 381, obtained from Dr Howard Kuramitsu at State University of Buffalo (Buffalo, NY, USA), was stored in DMSO at $-80{ }^{\circ} \mathrm{C}$ and revived on BAPHK plates, before transferring to Todd-Hewitt Broth containing $1 \mu \mathrm{g}$ haemin $\mathrm{ml}^{-1}$ and $1 \mu \mathrm{g}$ menadione $\mathrm{ml}^{-1}$ (THBHK).

Detection of biofilm inhibitory activity. The biofilm assay was performed as previously described (Davey, 2006; Davey \& Duncan, 2006), with slight modifications. Briefly, THBHK broth cultures were inoculated from BAPHK plates of $P$. gingivalis strain 381 and grown anaerobically for $36 \mathrm{~h}$. Broth cultures were then diluted in a chemically defined medium $(\mathrm{CDM})$ developed for $P$. gingivalis (Milner et al., 1996), supplemented with $1 \%$ tryptone, to $\mathrm{OD}_{600}$ 0.2. Culture aliquots of $200 \mu \mathrm{l}$ were then placed into 96-well polystyrene flat-bottom plates under aerobic conditions before anaerobic incubation (Pack-Anaero, Mitsubishi Gas Chemical
Company) at $37{ }^{\circ} \mathrm{C}$ for $24 \mathrm{~h}$. The culture supernatant was then removed by inversion and shaking, and the plate was washed twice by immersion in distilled water. The biofilm-containing plates were airdried, stained with $0.1 \%$ safranin for $15 \mathrm{~min}(100 \mu \mathrm{l}$ per well) and washed twice more in distilled water. The amount of biofilm was quantified by solubilizing the safranin in $90 \%$ ethanol/1.0\% SDS (200 $\mu \mathrm{l}$ per well) for $15 \mathrm{~min}$ before measuring absorbance (492 nm) with a plate reader.

To screen for biofilm inhibition by filter-sterilized spent supernatants, fractions from different stages of purification (see below) and aliquots of citrulline (final concentration $10 \mathrm{mM}$ ) were tested in triplicate by adding aliquots to the biofilm assay culture before anaerobic incubation. Through the dilution of a $2 \times$ concentrated CDM medium, samples of up to $100 \mu \mathrm{l}$ (twofold dilution) were tested while maintaining the final nutrient concentration at $1 \times \mathrm{CDM}$.

Biofilm-inhibitor production analysis. To determine if the inhibitor was produced only during certain phases of growth, a production analysis was performed. BHI broth cultures of the $S$. intermedius isolate were grown (in triplicate) and incubated anaerobically at $37{ }^{\circ} \mathrm{C}$ for $24 \mathrm{~h}$. Aliquots were withdrawn at regular intervals to measure cell density $\left(\mathrm{OD}_{600}\right)$ and to determine the titre of the effector in the culture supernatant. The activity was monitored using the biofilm assay, as described above. Cell-free spent supernatants that demonstrated activity at a dilution of $1: 10$ or greater were considered significant.

Protein purification. Our preliminary studies with protease (proteinase $\mathrm{K}$ ) treatment indicated that the inhibitor (effector) was a protein; therefore, ammonium sulfate precipitation followed by ion-exchange chromatography was used to purify the effector. The S. intermedius isolate was grown anaerobically at $37{ }^{\circ} \mathrm{C}$ to stationary phase in one litre of BHI broth (final $\mathrm{pH} \sim 7.4$ ). The cell-free supernatant was brought to $40 \%$ saturation with ammonium sulfate, stirred for $4 \mathrm{~h}$ at $4{ }^{\circ} \mathrm{C}$ and then centrifuged $(23200 \mathrm{~g}, 30 \mathrm{~min})$. The centrifugate was brought to $65 \%$ saturation with ammonium sulfate and stirred overnight at $4{ }^{\circ} \mathrm{C}$. The $40-65 \%$ ammonium sulfate precipitate was collected, dissolved in $25 \mathrm{ml} 10 \mathrm{mM}$ sodium phosphate buffer ( $\mathrm{pH} \mathrm{7.0)}$ and desalted by overnight dialysis (10 kDa molecular mass (weight) cut-off, MWCO) in $10 \mathrm{mM}$ sodium phosphate buffer $\left(\mathrm{pH} \mathrm{7.0)}\right.$ at $4{ }^{\circ} \mathrm{C}$. The material $(8 \mathrm{ml})$ was then applied to a $30 \mathrm{ml}$ DEAE Sepharose Fast Flow column (GE Healthcare) equilibrated with the same sodium phosphate buffer. The column was washed with 2 column volumes (CV) of equilibration buffer, one CV $100 \mathrm{mM} \mathrm{NaCl}$ and $3 \mathrm{CV} 200 \mathrm{mM} \mathrm{NaCl}$ before activity was eluted in $3 \mathrm{CV} 500 \mathrm{mM} \mathrm{NaCl}$ at a flow rate of $10 \mathrm{ml} \mathrm{min}^{-1}$. The activity was recovered in a $30 \mathrm{ml}$ fraction and desalted with a centrifugal filter device (Amicon Ultra-4, 10k, Millipore) along with buffer exchange to $20 \mathrm{mM}, \mathrm{pH} 6.0$. A portion $(0.5 \mathrm{ml})$ of the material was then applied to a Mono Q HR 5/5 FPLC column (Pharmacia) equilibrated with the Bistris/HCl buffer. The column was washed with $2 \mathrm{CV}$ equilibration buffer followed by a linear $\mathrm{NaCl}$ gradient from $0 \mathrm{mM} \mathrm{NaCl}$ to $200 \mathrm{mM} \mathrm{NaCl}$ over $6 \mathrm{CV}$. The $\mathrm{NaCl}$ concentration was held at $200 \mathrm{mM}$ for $4 \mathrm{CV}$, increased to $240 \mathrm{mM}$ over $1 \mathrm{CV}$ and kept at $240 \mathrm{mM}$ for $2 \mathrm{CV}$. Activity was eluted with $240 \mathrm{mM} \mathrm{NaCl}$ at a flow rate of $1 \mathrm{ml} \mathrm{min}^{-1}$ and recovered in a $1 \mathrm{ml}$ fraction. All column purification steps were run at room temperature. The Bio-Rad Bradford reagent (Bradford, 1976) was used to quantify the protein content with bovine gamma globulin as a standard.

Protein size determination during purification. Amicon spin columns were used to approximate the mass of the effector protein. Cell-free spent supernatant was applied to a centrifugal filter device with a MWCO of $100 \mathrm{kDa}$ (Amicon Ultra-4, 100k, Millipore). The retentate was kept for biofilm inhibition analysis while the flowthrough was applied to another filter device with a MWCO of $50 \mathrm{kDa}$. This above process was repeated for filter devices with 
MWCOs of 30,10 and $5 \mathrm{kDa}$. All retentates and the $5 \mathrm{kDa}$ flowthrough were tested for activity on biofilm formation using the biofilm assay described above.

PAGE analysis. To assess the purity of the protein and isolate it for sequence analysis, we used SDS-PAGE and native PAGE, respectively. For SDS-PAGE analysis, the purified fractions were mixed in sample buffer, heated at $100{ }^{\circ} \mathrm{C}$ for $5 \mathrm{~min}$ and then aliquots were analysed using $12 \%$ polyacrylamide gels. The samples were electrophoresed at a constant voltage $(70 \mathrm{~V})$ for approximately $4 \mathrm{~h}$. Following electrophoresis, silver staining (Bio-Rad) was used for detection. For native PAGE analysis $10 \%$ Tris/ $\mathrm{HCl}$ (Bio-Rad) was used with Tris/glycine running buffer $(25 \mathrm{mM}$ Tris/ $\mathrm{HCl}, 192 \mathrm{mM}$ glycine, $\mathrm{pH}$ 8.3). The samples were electrophoresed at a constant voltage $(200 \mathrm{~V})$ for 35 min and colloidal Coomassie blue (Novex, Invitrogen) was used for staining.

Proteomic sequence analysis. To identify the effector, the protein was excised from a native polyacrylamide gel and extracted by electroelution. Identification of the protein was performed at the Harvard Microchemistry and Proteomics Analysis Facility by using microcapillary reverse-phase HPLC nano-electrospray tandem mass spectrometry ( $\mu \mathrm{LC} / \mathrm{MS} / \mathrm{MS})$ on a Thermo LTQ-Orbitrap mass spectrometer.

Arginine deiminase assay. Protein sequence analysis indicated that the isolated protein was an arginine deiminase; therefore, enzymic assays were performed to verify this identification. The arginine deiminase activity was determined in 96 -well plates, as previously described (Xie et al., 2007).

Arginine deiminase treatment and RNA isolation. To examine the effect of the arginine deiminase protein on expression of genes ( $f m A$ and $m f a l$ ) encoding the major protein subunits of fimbriae, THBHK broth cultures of $P$. gingivalis strain 381 were grown anaerobically for $36 \mathrm{~h}$, then diluted in a chemically defined medium (CDM) developed for P. gingivalis (Milner et al., 1996), supplemented with $1 \%$ tryptone, to $\mathrm{OD}_{600} 0.2$. The culture was then split in two, and one culture was exposed to a 1:50 dilution of the desalted and lyophilized final active Mono Q fraction (see Fig. 4, lane G). The control (treated with a 1:50 dilution of PBS) and the treated cultures were incubated anaerobically for $1 \mathrm{~h}$ at $37^{\circ} \mathrm{C}$. The cells were then pelleted and an aliquot of supernatant $(100 \mu \mathrm{l})$ was removed for testing for the presence of citrulline (monitoring of arginine deiminase enzymic activity). Total RNA was then extracted using the MasterPure RNA purification kit (Epicentre) according to the manufacturer's instructions. Contaminating DNA was removed by digestion with turbo DNAse I (Ambion) followed by acid-phenol/ chloroform extraction. The quality of the RNA was determined by agarose gel electrophoresis and the concentration was determined using a NanoDrop N-100 spectrophotometer (NanoDrop technologies). This treatment protocol and total RNA extraction were performed three times (three biological replicates).

Quantitative reverse transcription-PCR (qPCR). For cDNA generation, $1 \mu \mathrm{g}$ total RNA was reverse transcribed with random 9mer primers using the MonsterScript 1st-Strand cDNA Synthesis kit according to the manufacturer's protocol (Epicentre). Primers were designed using DNASTAR Lasergene software. The primer sequences used are as follows: for fimA, fimA-381F-qPCR 5'-CTGCCGCCGATGCTCCTC-3' and fimA-381R-qPCR $5^{\prime}$-CAAGTCGGCTCCGTTTTTCTGA-3'; for $m f a 1$, mfal-381F-qPCR $5^{\prime}$-GGATATCAGATGGGTTGTTGCTCA-3' and mfal-381R-qPCR 5'-TGTATGGAAAGTGCTGCTGGTAGG- $3^{\prime}$. The product sizes for the fimA and the $m f a 1$ probes were $122 \mathrm{bp}$ and $130 \mathrm{bp}$, respectively. The 16s rRNA gene was used as a reference, and the sequences of the forward and reverse primers used are as follows: 16s-Forw $5^{\prime}$-TGTTACAATGGGAGGG-
ACAAAGGG-3' and 16S-Rev 5' ${ }^{\prime}$-TTACTAGCGAATCCAGCTTCACGG-3'. qPCR was carried out with a Bio-Rad iCycler using SYBR Green Supermix (Bio-Rad). The qPCR consisted of an initial denaturation step at $95{ }^{\circ} \mathrm{C}$ for $3 \mathrm{~min}$, followed by 50 cycles of $95{ }^{\circ} \mathrm{C}$ for $15 \mathrm{~s}, 60{ }^{\circ} \mathrm{C}$ for 15 sand $72{ }^{\circ} \mathrm{C}$ for $15 \mathrm{~s}$. A melting curve profile for each amplified PCR product was determined using the following conditions: $95{ }^{\circ} \mathrm{C}$ for $1 \mathrm{~min}, 55{ }^{\circ} \mathrm{C}$ for $1 \mathrm{~min}$, followed by 80 cycles of $10 \mathrm{~s}$ with a temperature increase of $0.5{ }^{\circ} \mathrm{C}$ for each cycle, starting at $55{ }^{\circ} \mathrm{C}$.

Growth inhibition analysis. To determine if the biofilm inhibitor affected the growth rate of $P$. gingivalis, growth curves were determined in the presence and absence of the partially purified inhibitor (the active fraction obtained from the DEAE purification step described above; capable of biofilm inhibition up to a dilution of $1: 40)$. To perform these experiments, a THBHK broth culture of $P$. gingivalis was grown anaerobically to early exponential phase $\left(\mathrm{OD}_{600}\right.$ $\sim 0.3)$. Aliquots $(4.75 \mathrm{ml})$ of the culture were mixed in triplicate with either $0.25 \mathrm{ml}$ of pre-reduced $20 \mathrm{mM}$ Bistris/HCl; pH 6 (buffer control), or $0.25 \mathrm{ml}$ of the active DEAE fraction (dialysed against $20 \mathrm{mM}$ Bistris/ $\mathrm{HCl} ; \mathrm{pH}$ 6) to make a final dilution of $1: 20$. Cultures were then incubated anaerobically at $37{ }^{\circ} \mathrm{C}$ for $12 \mathrm{~h}$, with aliquots being withdrawn at regular intervals to monitor growth, measured as $\mathrm{OD}_{600}$.

Identification of the clinical isolate as Streptococcus intermedius. To identify the clinical isolate, sequencing of the 16S rRNA gene was performed and the sequence was compared to the Human Oral Microbiome Database (HOMD) by Dr Floyd Dewhirst's laboratory at The Forsyth Institute (http://www.HOMD.org) (Chen et al., 2010; Dewhirst et al., 2010). The clinical isolate was identified as a Streptococcus intermedius and the genome of this strain is presently being sequenced.

\section{RESULTS}

\section{Screening of spent supernatants}

Spent supernatants from 79 clinical streptococcal strains were tested (twofold and tenfold dilutions) for their ability to inhibit or enhance $P$. gingivalis biofilm formation. The majority of supernatants (61 isolates) resulted in the lysis of $P$. gingivalis cells and some (17 isolates) had no effect on cell viability, growth, or biofilm formation. However, one of the clinical strains (identified as Streptococcus intermedius) produced a supernatant that completely abolished biofilm formation at both a twofold and a tenfold dilution, with no effect on growth rate. Purification and characterization of the protein responsible for this extracellular activity is the focus of this report.

\section{Production of the effector protein in relation to growth phase}

In order to assess whether cell density played a role in release of the activity into the culture supernatant, production of the inhibitor was determined during various phases of growth in BHI broth. A profile of growth in relation to inhibitory activity, and a dilution series of the spent supernatant (18 h culture) are shown in Fig. 1(a, b). High levels of inhibitory activity (from at least $1: 10$ dilution of spent supernatant) were detected as early as the 
(a)

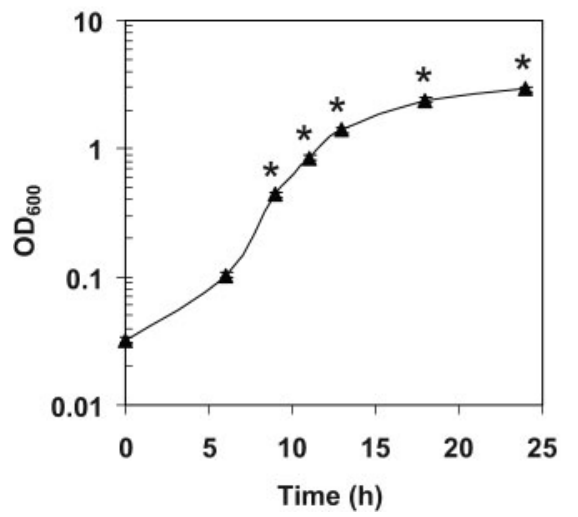

(b)

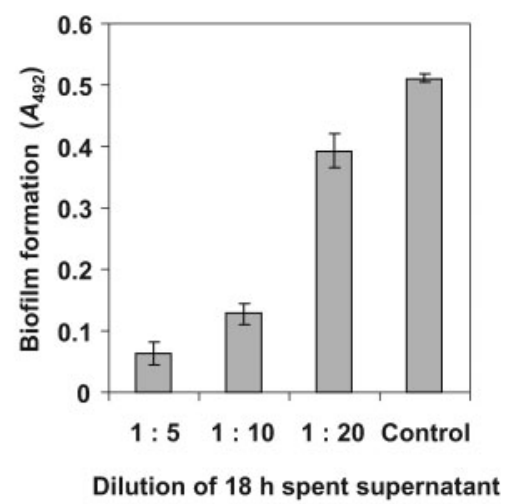

Fig. 1. Detection of biofilm inhibitory activity in the spent supernatant of the clinical strain of $S$. intermedius grown in $B H I$ broth at $37{ }^{\circ} \mathrm{C}$ for $24 \mathrm{~h}$. (a) Inhibitory activity $\left(^{*}\right)$ was detected in mid- and late-exponential growth and during stationary phase. (b) Effect of $18 \mathrm{~h}$ spent supernatant on biofilm formation. Supernatant obtained after $18 \mathrm{~h}$ anaerobic growth significantly inhibited $P$. gingivalis biofilm formation at all dilutions tested. Results are means $\pm \mathrm{SD}(n=3)$.

mid-exponential growth phase $\left(\mathrm{OD}_{600} 0.4\right)$ and throughout exponential growth (indicated by asterisks in Fig. 1a), paralleling the increase in biomass. The levels of activity reached a maximum as the culture entered stationary phase, again paralleling biomass levels.

\section{Effect on growth rate}

To determine whether biofilm inhibition was the result of growth restriction, the target organism, $P$. gingivalis strain 381, was grown in the presence (and absence) of the partially purified biofilm inhibitor (DEAE active fraction) at a $1: 20$ dilution, which is two times more concentrated than the dilution that inhibited biofilm formation. Growth was assessed at $\mathrm{OD}_{600}$ over time. The results, summarized in Fig. 2, show that although biofilm formation was inhibited with this fraction there was no effect on $P$. gingivalis growth.

\section{Purification and characterization of the effector protein}

During purification, size fractionation using centrifugal filter devices (Amicon) allowed for a rough estimate of the protein's mass. Activity was recovered in the $50 \mathrm{kDa}$ filter device flow-through/30 kDa filter device retentate, while the other size fractions lacked activity (data not shown). The mass of the active compound was thereby estimated to be in the range between 30 and $50 \mathrm{kDa}$.

$P$. gingivalis biofilm assays were used to monitor purification of the inhibitory activity. Representative data from a biofilm assay are shown in Fig. 3(a). Dialysed fractions eluted from the DEAE column with $500 \mathrm{mM} \mathrm{NaCl}$ demonstrated strong inhibitory activity (Fig. 3a). This fraction was then applied to a Mono Q column and of those fractions eluted at a linear $\mathrm{NaCl}$ gradient from 0 to $600 \mathrm{mM}$, activity was recovered in one fraction between 200 and $240 \mathrm{mM} \mathrm{NaCl}$ (Fig. 3a, Mono Q2 fraction). To further purify the protein, the active fraction from the first Mono Q column (Mono Q2) was applied to a second Mono Q column. This column was then run with a flatter gradient ranging from 200 to $240 \mathrm{mM} \mathrm{NaCl}$. When the purity of the fractions obtained from the second Mono $\mathrm{Q}$ column was assessed by SDS-PAGE analysis, only one protein band was present in all lanes that were loaded with an active fraction (Fig. 3b). Conversely, this band

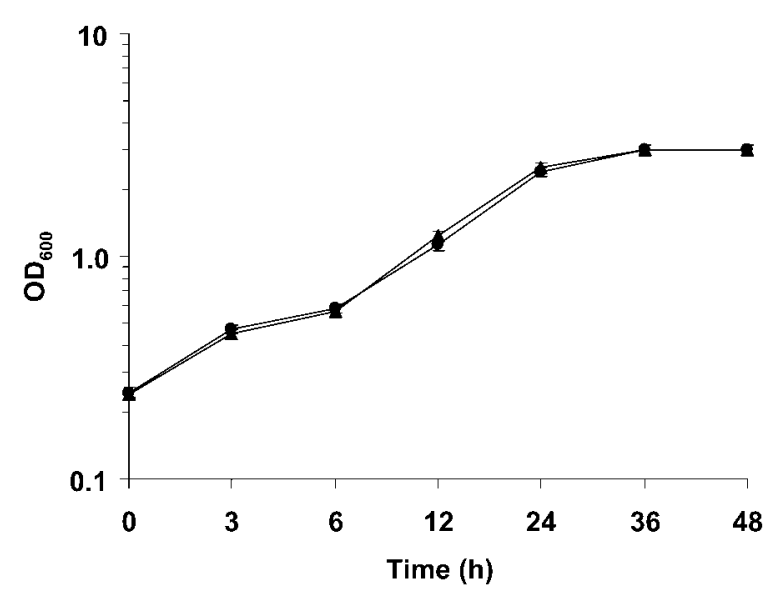

Fig. 2. Growth curves of $P$. gingivalis in the presence or absence of biofilm inhibitor. The dilution of partially purified biofilm inhibitor (DEAE fraction; Fig. 3b, lane B) was 20-fold diluted (O) compared to the control buffer $(\boldsymbol{A})$. The addition of the arginine deiminase had no effect on the growth rate of $P$. gingivalis. 
(a)

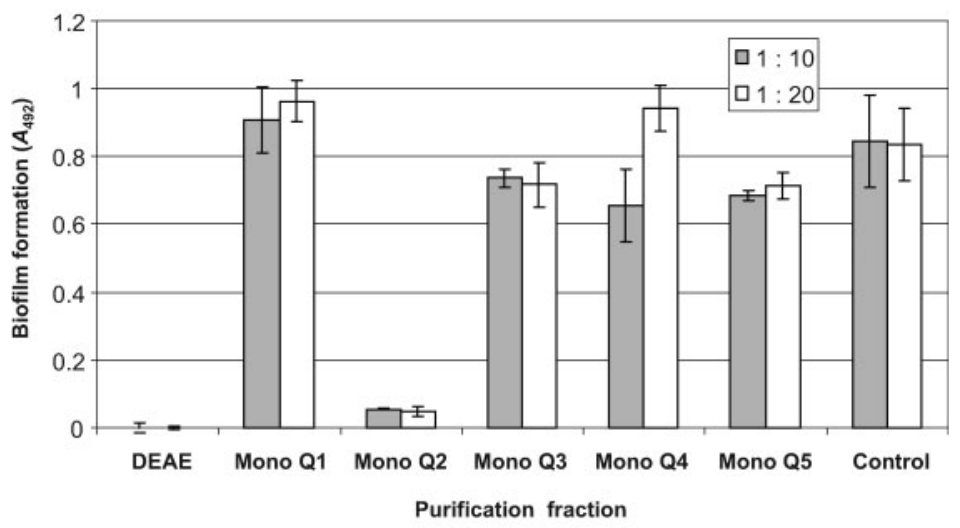

(b)

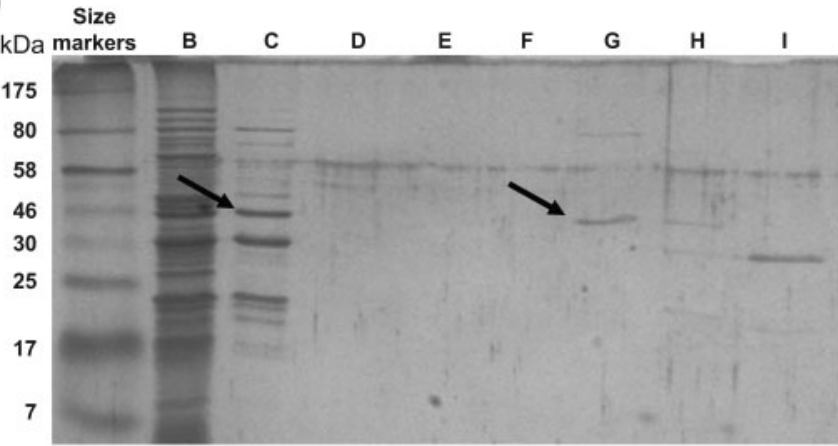

(c)

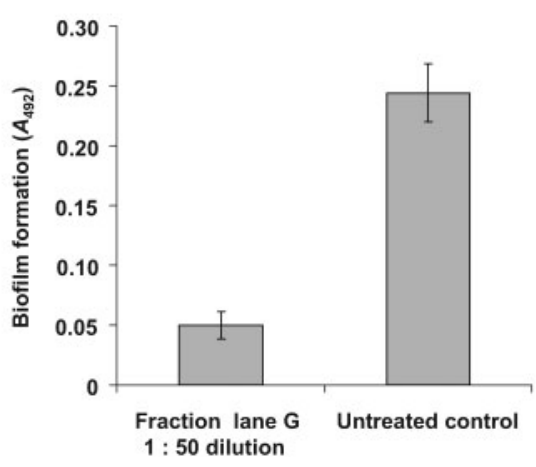

Fig. 3. (a) Biofilm assays were used to monitor the biofilm inhibitory activity during purification from the spent supernatant. Samples of the fraction eluted from the DEAE column using $500 \mathrm{mM} \mathrm{NaCl}$ (DEAE) and fractions eluted from a Mono $\mathrm{Q}$ column using between 0 and $600 \mathrm{mM} \mathrm{NaCl}$ (Mono Q 1-5) were tested in the biofilm assay, in triplicate, at dilutions of $1: 10$ and $1: 20$. Note: the active fraction applied to Mono Q2 eluted from the Mono Q column within the 200 to $240 \mathrm{mM} \mathrm{NaCl}$ range. Results are means $\pm S D(n=3)$. (b) Samples of the active fraction from the DEAE column (lane B) and of the subsequent fractions from the Mono $\mathrm{Q}$ columns (lanes $\mathrm{C}-\mathrm{H}$ ) were submitted to SDS-PAGE analysis. Proteins were detected with silver staining. The material applied to lane $B$ corresponds to the fraction tested in the biofilm assay in (a) (DEAE). Lane C contains an active fraction of all material eluted from 200 to $240 \mathrm{mM} \mathrm{NaCl}$ [corresponding to material applied in (a) Mono Q 2], while lanes D-I contain material eluted serially within the 200 to $240 \mathrm{mM} \mathrm{NaCl}$ range, at a flatter gradient. Of these, the greatest activity was observed in the material applied to lane G, which contained a prominent $\sim 48 \mathrm{kDa}$ band (marked with arrow). (c) Effect of a 1:50 dilution (final concentration $\leqslant 3.8 \mu \mathrm{g}$ arginine deiminase $\mathrm{ml}^{-1}$ ) of the purified fraction (lane $\mathrm{G}$ ) on $P$. gingivalis biofilm formation. The results show a significant inhibition $(P<0.0001)$ of biofilm formation when compared to the untreated control. Results are means $\pm S D(n=3)$.
( $\sim 48 \mathrm{kDa})$ was absent in all lanes that were loaded with an inactive fraction. The most pure fraction (Fig. 3b, lane $G$ ) contained one other protein at $\sim 80 \mathrm{kDa}$. However, our studies had already determined that the active protein was between 30 and $50 \mathrm{kDa}$; therefore, the $48 \mathrm{kDa}$ protein was isolated and analysed. This fraction was highly active, inhibiting $P$. gingivalis biofilm formation out to a $1: 80$ dilution. Inhibition at a $1: 50$ dilution (final arginine deiminase concentration, $\leqslant 3.8 \mu \mathrm{g} \mathrm{ml}^{-1}$ ) is shown in Fig. 3(c).

Native PAGE was used to isolate the active protein for identification, and protein sequence analysis (see below) identified the $48 \mathrm{kDa}$ band as an arginine deiminase. The identification was then confirmed with an enzymic assay for arginine deiminase (see Fig. 4).

\section{Proteomic sequence analysis}

The $48 \mathrm{kDa}$ protein band was excised from a native polyacrylamide gel and the protein extracted by electroelution. Identification of the protein was determined at the Harvard Microchemistry and Proteomics Analysis Facility by $\mu \mathrm{LC} / \mathrm{MS} / \mathrm{MS}$ on a Thermo LTQ-Orbitrap mass spectrometer. The highest similarity was to arginine deiminases (ArcA) of oral streptococci, i.e. Streptococcus gordonii (strain Challis/ATCC 35105) and Streptococcus sanguinis (strain SK36). Forty-eight cleavage products (50.1\% coverage) matched ArcA from S. gordonii. The sequences of all of these tryspin cleavage products aligned to the S. gordonii ArcA protein coding region (data not shown), as well as four additional tryspin cleavage products that matched S. sanguinis. We concluded that the purified 


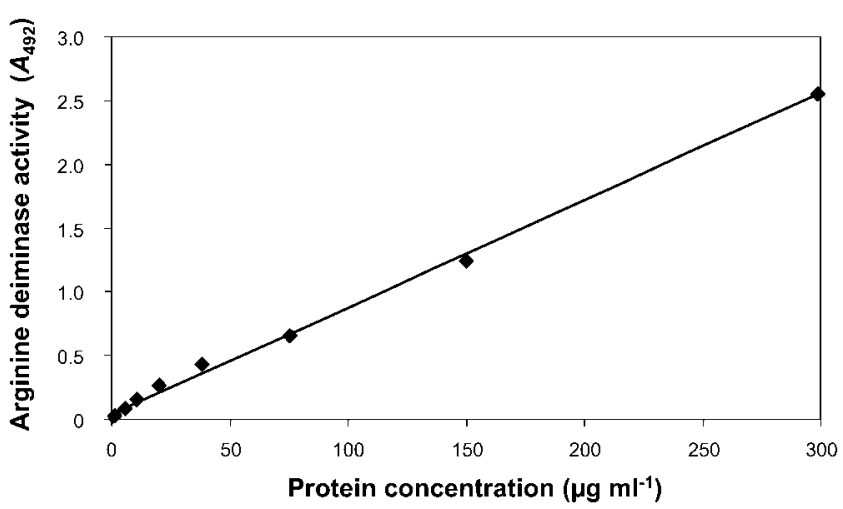

Fig. 4. Arginine deiminase activity of purified protein. Serial twofold dilutions (highest concentration $300 \mu \mathrm{g} \mathrm{ml}^{-1}$ ) of the $S$. intermedius purified protein were tested in a colorimetric assay for arginine deiminase activity. The enzymic activity of the purified protein demonstrated a linear dependence on the protein concentration.

effector protein was an arginine deiminase; this was confirmed with an enzyme assay for arginine deiminase activity, corroborating the sequence data.

\section{Expression analysis of fimA and $m f a 1$ in response to arginine deiminase exposure}

Previous studies reported that a cell-wall-associated arginine deiminase produced by the oral streptococcus $S$. cristatus caused a downregulation of fimbriae expression in a cell-to-cell contact dependent manner. Since both short and long fimbriae have been shown to play a key role in $P$. gingivalis biofilm development, we hypothesized that the arginine deiminase isolated in our studies may also be acting, in part, by downregulating the expression of fimbriae. Therefore, qPCR was used to examine the expression of the fimA and the $m f a l$ genes in response to arginine deiminase exposure for $1 \mathrm{~h}$. A 1:50 dilution of the final Mono Q purified fraction, corresponding to a final arginine deiminase concentration of $\leqslant 3.8 \mu \mathrm{g} \mathrm{ml}^{-1}$, was used in this experiment. As shown in Fig. 5, expression of both $\operatorname{fimA}$ and $m f a 1$ were significantly downregulated when $P$. gingivalis strain 381 cells were exposed to the arginine deiminase produced by $S$. intermedius.

In addition, we hypothesized that this change in $P$. gingivalis gene expression could be triggered by arginine deiminase enzymic activity (i.e. production of citrulline or removal of arginine). To investigate this hypothesis, we tested for citrulline production (using the final step of the arginine deiminase assay) after $1 \mathrm{~h}$ exposure to the enzyme and no citrulline was detected (limit of detection in the linear range is $1.4 \mathrm{mM}$ ), indicating that enzymic activity did not occur during exposure, yet signalling was detected. Furthermore, the addition of citrulline $(10 \mathrm{mM})$ did not inhibit $P$. gingivalis biofilm formation (data not shown). Overall, our data are consistent with previous reported

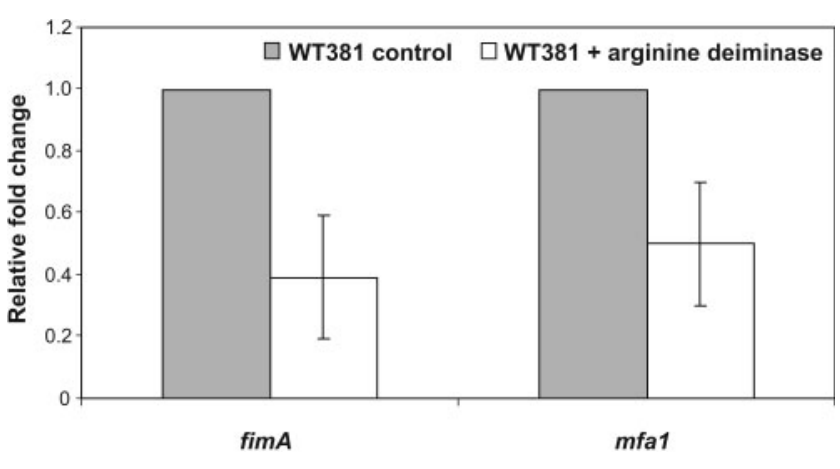

Fig. 5. $\mathrm{qPCR}$ analysis of the fim $A(0.41 \pm 0.2$-fold change, $P$-value $0.006)$ and $m f a 1(0.50 \pm 0.2$-fold change, $P$-value 0.011$)$ genes in $P$. gingivalis cells exposed to the purified arginine deiminase. A $1: 50$ dilution of the protein corresponds to $\leqslant 3.8 \mu \mathrm{g}$ arginine deiminase $\mathrm{ml}^{-1}$. The data presented are means of three separate datasets. Error bars represent SEM.

data showing that enzymic activity is not required for signalling.

\section{DISCUSSION}

A key determinant that regulates colonization and virulence in $P$. gingivalis is the expression of fimbriae. Two distinct fimbrial structures are present on the surface of $P$. gingivalis cells: the long fimbriae, primarily consisting of FimA protein subunits, and the short fimbriae, composed of the Mfa1 subunit. Studies have demonstrated a role for long fimbriae in adherence to and invasion of gingival epithelial cells, bone resorption, co-aggregation with other oral isolates, and biofilm formation (Amano et al., 2004; Hamada et al., 1998; Lamont \& Jenkinson, 1998). Interestingly, it was recently shown that the short fimbriae, unlike the long fimbriae, are required for autoaggregation (Lin et al., 2006), indicating that these two surface structures have distinctive functions. The in vivo signals that trigger the expression of genes involved in the biogenesis of fimbriae are not known; however, it has been shown that expression is affected by environmental and nutritional parameters. Expression of fimA is repressed under elevated temperatures or when iron is limiting (Amano et al., 1994; McKee et al., 1986; Xie et al., 1997). In addition, the molecular mechanism involved in the regulation of fimA expression is beginning to be understood. A two-component system (FimS-FimR) that regulates expression has been identified (Hayashi et al., 2000; Watanabe-Kato et al., 1998; Watanabe et al., 1996), and recently it was shown that the response regulator of this two-component system (FimR) controls the expression of these genes at the transcription level (Nishikawa et al., 2004). In regard to $m f a 1$, expression of this gene has been shown to be affected by cell-to-cell contact with a variety of oral streptococci; either upregulation or downregulation was observed, depending on the species (Park et al., 2006). 
Likewise, fimA expression has been shown to be affected by cell-to-cell contact, specifically with $S$. cristatus, and an arginine deiminase on the surface of the cell was shown to be responsible for this change in expression (Xie et al., 2007). Furthermore, those data indicate that downregulation occurred in the absence of arginine deiminase enzymic activity.

Here, we show that the transcription of both fimA and $m f a 1$ was downregulated when $P$. gingivalis strain 381 was exposed for $1 \mathrm{~h}$ to an arginine deiminase purified from the supernatant of a $S$. intermedius clinical isolate and, as for the arginine deiminase isolated from $S$. cristatus, enzymic activity is not involved in signalling. Unfortunately, the addition of arginine deiminase inhibitors (lysine, formamidine and aminoguanidine) at recommended concentrations led to growth defects of $P$. gingivalis so we were not able to employ these reagents in our analyses. Our future intentions are to generate an inactive form of the arginine deiminase and compare the response of $P$. gingivalis to the enzymically active and inactive forms. Our current working hypothesis is that this arginine deiminase protein is secreted and acts as an effector, possibly signalling via an interaction with a receptor on the cell surface of $P$. gingivalis.

Arginine deiminase is the first enzyme in an anaerobic energy-generating pathway (the ADI pathway) that catalyses the conversion of L-arginine to ornithine, ammonia and carbon dioxide with the concomitant synthesis of ATP (Cunin et al., 1986). Arginine deiminase catalyses the hydrolysis of L-arginine to L-citrulline and ammonia. The release of ammonia from this reaction can neutralize acids produced through glycolysis, thereby raising the $\mathrm{pH}$ of the environment. The increase in $\mathrm{pH}$ resulting from arginine catabolism by oral streptococci (as well as other oral isolates) is believed to play an important role in inhibiting tooth decay and in modulating the microbial composition of the oral biofilm (Burne \& Marquis, 2000; Nascimento et al., 2009). Interestingly, all of the enzymes in the ADI pathway, along with a variety of other proteins typically thought of as being cytoplasmically localized, have been identified as being cell-surface associated in a diverse number of streptococci (Cole et al., 2005), including the arginine deiminase of S. cristatus (Xie et al., 2000; Xie et al., 2007). Furthermore, ADI enzymes have been detected in culture supernatants of streptococci (Lei et al., 2000). Interestingly, these proteins lack a secretion signal sequence or an LPXTG membrane-anchoring sequence; hence, the mechanism by which these enzymes are transported or localized to the cell surface is unknown. It has been proposed that an internal sequence, a post-translational acylation, or an association with another secreted protein may be involved (Cole et al., 2005). Furthermore, if these proteins are localized to the cell surface and then released, the mechanism of release from the cell surface is unknown. The protein sequence data we obtained from our analysis indicate that the extracellular arginine deiminase we identified is intact, i.e. cleavage products from both the $\mathrm{C}$ terminus and the $\mathrm{N}$ terminus of the protein-coding region were identified, indicating that the protein is not likely to have been cleaved from the cell surface. Furthermore, the protein was detected during mid-exponential growth. This would indicate that the protein is either secreted or released by an unknown mechanism. Further studies are required to determine how this protein makes it to the supernatant.

As a result of the present study, as well as previous studies by Xie et al. $(2000,2007)$, it is becoming evident that $P$. gingivalis is able to sense arginine deiminase proteins produced by oral streptococci and respond by altering the expression of key surface structures that are required for colonization. Although this is not the first report of an arginine deiminase produced by an oral streptococcus that signals $P$. gingivalis to downregulate fimbriae expression, this is believed to be the first report of an extracellular form of arginine deiminase being able to downregulate fimbriae expression, thus providing an added dimension to this inter-species communication. In addition, although the previously reported arginine deiminase did not affect expression of $m f a 1$ in strain 33277 , our data indicate that the protein described here affects expression of both fimA and $m f a 1$ in strain 381 ; thus this effector protein may trigger a different response in different strains of $P$. gingivalis. It was recently discovered that another bacterium that is an indigenous member of the human oral microbiota (Granulicatella elegans) also produces an extracellular arginine deiminase that inhibits the proliferation of mitogen-stimulated human peripheral blood mononuclear cells (Kanamoto et al., 2007). Growth inhibition of various human cell lines has also been reported for arginine deiminases from Streptococcus pyogenes and Mycoplasma arginini, and although some of this growth-inhibitory activity has been attributed to the depletion of arginine, in studies of the M. arginini arginine deiminase the effect was observed even in arginine-free medium, again supporting the model that signalling is not merely due to the lack of arginine in the medium or the influence of arginine deiminase-yielded end products (Degnan et al., 1998; Gong et al., 1999, 2000). Thus, these arginine deiminases appear to be moonlighting as effectors not only between different genera of prokaryotes, but also between prokaryotic and eukaryotic cells. Our future studies are designed to further our understanding of this signalling mechanism.

\section{ACKNOWLEDGEMENTS}

This work was supported by a grant from the Colgate Palmolive Company.

\section{REFERENCES}

Amano, A., Sharma, A., Sojar, H. T., Kuramitsu, H. K. \& Genco, R. J. (1994). Effects of temperature stress on expression of fimbriae and superoxide dismutase by Porphyromonas gingivalis. Infect Immun 62, 4682-4685. 
Amano, A., Nakagawa, I., Okahashi, N. \& Hamada, N. (2004). Variations of Porphyromonas gingivalis fimbriae in relation to microbial pathogenesis. J Periodontal Res 39, 136-142.

Barnard, J. P. \& Stinson, M. W. (1999). Influence of environmental conditions on hydrogen peroxide formation by Streptococcus gordonii. Infect Immun 67, 6558-6564.

Bradford, M. M. (1976). A rapid and sensitive method for the quantitation of microgram quantities of protein utilizing the principle of protein-dye binding. Anal Biochem 72, 248-254.

Burne, R. A. \& Marquis, R. E. (2000). Alkali production by oral bacteria and protection against dental caries. FEMS Microbiol Lett 193, 1-6.

Chen, T., Yu, W.-H., Izard, J., Baranova, O. V., Lakshmanan, A. \& Dewhirst, F. E. (2010). The Human Oral Microbiome Database: a web accessible resource for investigating oral microbe taxonomic and genomic information. Database (in press), doi:10.1093/database/ baq013

Chikindas, M. L., Novak, J., Driessen, A. J., Konings, W. N., Schilling, K. M. \& Caufield, P. W. (1995). Mutacin II, a bactericidal antibiotic from Streptococcus mutans. Antimicrob Agents Chemother 39, 26562660.

Choi, J. I., Nakagawa, T., Yamada, S., Takazoe, I. \& Okuda, K. (1990). Clinical, microbiological and immunological studies on recurrent periodontal disease. J Clin Periodontol 17, 426-434.

Cole, J. N., Ramirez, R. D., Currie, B. J., Cordwell, S. J., Djordjevic, S. P. \& Walker, M. J. (2005). Surface analyses and immune reactivities of major cell wall-associated proteins of group a streptococcus. Infect Immun 73, 3137-3146.

Cunin, R., Glansdorff, N., Pierard, A. \& Stalon, V. (1986). Biosynthesis and metabolism of arginine in bacteria. Microbiol Rev 50, 314-352.

Davey, M. E. (2006). Techniques for the growth of Porphyromonas gingivalis biofilms. Periodontol 2000 42, 27-35.

Davey, M. E. \& Costerton, J. W. (2006). Molecular genetics analyses of biofilm formation in oral isolates. Periodontol 2000 42, 13-26.

Davey, M. E. \& Duncan, M. J. (2006). Enhanced biofilm formation and loss of capsule synthesis: deletion of a putative glycosyltransferase in Porphyromonas gingivalis. J Bacteriol 188, 5510-5523.

Degnan, B. A., Palmer, J. M., Robson, T., Jones, C. E., Fischer, M., Glanville, M., Mellor, G. D., Diamond, A. G., Kehoe, M. A. \& Goodacre, J. A. (1998). Inhibition of human peripheral blood mononuclear cell proliferation by Streptococcus pyogenes cell extract is associated with arginine deiminase activity. Infect Immun 66, 3050-3058.

Dewhirst, F. E., Chen, T., Izard, J., Paster, B. J., Tanner, A. C. R., Yu, W.-H., Lakshmanan, A. \& Wade, W. G. (2010). The Human Oral Microbiome. J Bacteriol (in press), doi: 10.1128/JB.00542-10.

Dzink, J. L., Socransky, S. S. \& Haffajee, A. D. (1988). The predominant cultivable microbiota of active and inactive lesions of destructive periodontal diseases. J Clin Periodontol 15, 316-323.

Falkow, S. (2006). Is persistent bacterial infection good for your health? Cell 124, 699-702.

Gong, H., Zolzer, F., von Recklinghausen, G., Rossler, J., Breit, S., Havers, W., Fotsis, T. \& Schweigerer, L. (1999). Arginine deiminase inhibits cell proliferation by arresting cell cycle and inducing apoptosis. Biochem Biophys Res Commun 261, 10-14.

Gong, H., Zolzer, F., von Recklinghausen, G., Havers, W. \& Schweigerer, L. (2000). Arginine deiminase inhibits proliferation of human leukemia cells more potently than asparaginase by inducing cell cycle arrest and apoptosis. Leukemia 14, 826-829.

Grossi, S. G., Zambon, J. J., Ho, A. W., Koch, G., Dunford, R. G., Machtei, E. E., Norderyd, O. M. \& Genco, R. J. (1994). Assessment of risk for periodontal disease. I. Risk indicators for attachment loss. J Periodontol 65, 260-267.

Hamada, S., Amano, A., Kimura, S., Nakagawa, I., Kawabata, S. \& Morisaki, I. (1998). The importance of fimbriae in the virulence and ecology of some oral bacteria. Oral Microbiol Immunol 13, 129-138.

Hayashi, J., Nishikawa, K., Hirano, R., Noguchi, T. \& Yoshimura, F. (2000). Identification of a two-component signal transduction system involved in fimbriation of Porphyromonas gingivalis. Microbiol Immunol 44, 279-282.

Jakubovics, N. S., Gill, S. R., Vickerman, M. M. \& Kolenbrander, P. E. (2008). Role of hydrogen peroxide in competition and cooperation between Streptococcus gordonii and Actinomyces naeslundii. FEMS Microbiol Ecol 66, 637-644.

Kanamoto, T., Sato, S., Nakashima, H. \& Inoue, M. (2007). Proliferation of mitogen-stimulated human peripheral blood mononuclear cells is inhibited by extracellular arginine deiminase of Granulicatella elegans isolated from the human mouth. J Infect Chemother 13, 353-355.

Kolenbrander, P. E., Andersen, R. N., Blehert, D. S., Egland, P. G., Foster, J. S. \& Palmer, R. J., Jr (2002). Communication among oral bacteria. Microbiol Mol Biol Rev 66, 486-505.

Kreth, J., Merritt, J., Shi, W. \& Qi, F. (2005). Competition and coexistence between Streptococcus mutans and Streptococcus sanguinis in the dental biofilm. J Bacteriol 187, 7193-7203.

Kuramitsu, H. K., He, X., Lux, R., Anderson, M. H. \& Shi, W. (2007). Interspecies interactions within oral microbial communities. Microbiol Mol Biol Rev 71, 653-670.

Lamont, R. J. \& Jenkinson, H. F. (1998). Life below the gum line: pathogenic mechanisms of Porphyromonas gingivalis. Microbiol Mol Biol Rev 62, 1244-1263.

Lamont, R. J. \& Yilmaz, O. (2002). In or out: the invasiveness of oral bacteria. Periodontol 2000 30, 61-69.

Lei, B., Mackie, S., Lukomski, S. \& Musser, J. M. (2000). Identification and immunogenicity of group A Streptococcus culture supernatant proteins. Infect Immun 68, 6807-6818.

Lin, X., Wu, J. \& Xie, H. (2006). Porphyromonas gingivalis minor fimbriae are required for cell-cell interactions. Infect Immun 74, 6011-6015.

McKee, A. S., McDermid, A. S., Baskerville, A., Dowsett, A. B., Ellwood, D. C. \& Marsh, P. D. (1986). Effect of hemin on the physiology and virulence of Bacteroides gingivalis W50. Infect Immun 52, 349-355.

Milner, P., Batten, J. E. \& Curtis, M. A. (1996). Development of a simple chemically defined medium for Porphyromonas gingivalis: requirement for alpha-ketoglutarate. FEMS Microbiol Lett 140, 125130 .

Moore, W. E., Moore, L. H., Ranney, R. R., Smibert, R. M., Burmeister, J. A. \& Schenkein, H. A. (1991). The microflora of periodontal sites showing active destructive progression. J Clin Periodontol 18, 729739.

Nascimento, M. M., Gordan, V. V., Garvan, C. W., Browngardt, C. M. \& Burne, R. A. (2009). Correlations of oral bacterial arginine and urea catabolism with caries experience. Oral Microbiol Immunol 24, 89-95.

Nishikawa, K., Yoshimura, F. \& Duncan, M. J. (2004). A regulation cascade controls expression of Porphyromonas gingivalis fimbriae via the FimR response regulator. Mol Microbiol 54, 546-560.

Park, Y., James, C. E., Yoshimura, F. \& Lamont, R. J. (2006). Expression of the short fimbriae of Porphyromonas gingivalis is regulated in oral bacterial consortia. FEMS Microbiol Lett 262, 6571 . 
Qi, F., Chen, P. \& Caufield, P. W. (1999). Purification of mutacin III from group III Streptococcus mutans UA787 and genetic analyses of mutacin III biosynthesis genes. Appl Environ Microbiol 65, 38803887.

Qi, F., Chen, P. \& Caufield, P. W. (2001). The group I strain of Streptococcus mutans, UA140, produces both the lantibiotic mutacin I and a nonlantibiotic bacteriocin, mutacin IV. Appl Environ Microbiol 67, 15-21.

Socransky, S. S. \& Haffajee, A. D. (2000). Dental biofilms: difficult therapeutic targets. Periodontol 2000 28, 12-55.

Upton, M., Tagg, J. R., Wescombe, P. \& Jenkinson, H. F. (2001).

Intra- and interspecies signaling between Streptococcus salivarius and Streptococcus pyogenes mediated by SalA and SalAl lantibiotic peptides. J Bacteriol 183, 3931-3938.

Watanabe, K., Onoe, T., Ozeki, M., Shimizu, Y., Sakayori, T., Nakamura, H. \& Yoshimura, F. (1996). Sequence and product analyses of the four genes downstream from the fimbrilin gene (fimA) of the oral anaerobe Porphyromonas gingivalis. Microbiol Immunol 40, 725734.
Watanabe-Kato, T., Hayashi, J. I., Terazawa, Y., Hoover, C. I., Nakayama, K., Hibi, E., Kawakami, N., Ikeda, T., Nakamura, H. \& other authors (1998). Isolation and characterization of transposoninduced mutants of Porphyromonas gingivalis deficient in fimbriation. Microb Pathog 24, 25-35.

Xie, H., Cai, S. \& Lamont, R. J. (1997). Environmental regulation of fimbrial gene expression in Porphyromonas gingivalis. Infect Immun 65, 2265-2271.

Xie, H., Cook, G. S., Costerton, J. W., Bruce, G., Rose, T. M. \& Lamont, R. J. (2000). Intergeneric communication in dental plaque biofilms. J Bacteriol 182, 7067-7069.

Xie, H., Lin, X., Wang, B. Y., Wu, J. \& Lamont, R. J. (2007). Identification of a signalling molecule involved in bacterial intergeneric communication. Microbiology 153, 3228-3234.

Yilmaz, O. (2008). The chronicles of Porphyromonas gingivalis: the microbium, the human oral epithelium and their interplay. Microbiology 154, 2897-2903.

Edited by: R. Palmer 